\title{
O EDUCADOR E A ESCOLA DE TEMPO INTEGRAL NO BRASIL: QUEM VAI "FAZER ACONTECER"?
}

\author{
The educator and school full time in Brazil: who will "make it happen"?
}

Educador y escuela de tiempo completo en Brasil: ¿quién va a "hacerlo realidad "?

\author{
Mercês P. Cunha Mendonça * \\ Iolene Mesquita Lobato * \\ Edna Perpetua dos Santos *
}

\begin{abstract}
Resumo
O artigo discorre sobre o papel do educador na educação integral e integrada no Brasil. Pretende-se analisar como o modelo integral foi construído, implementado e como está sendo revisto, bem como as necessidades de interação dos diversos atores no processo de EII. Também discute os requisitos de uma educação integral e integrada e o nível de preparação docente para implementação desse modelo. Sugerem-se questionamentos sobre a importância do professor enquanto implementador, analisador, catalisador de melhorias e aprendizado, enfim, protagonista do processo de EII e busca-se ao final ressaltar que melhorias, ainda, podem ser feitas para que o "filtro" pelo qual todo aluno passa esteja cada vez mais eficaz em sua função.
\end{abstract}

PALAVRAS-CHAVE: Educação Integral. Implementação. Professor.

\begin{abstract}
The article discusses the role of educator in holistic education and integrated in Brazil. The aim is to analyze how the integrated model was built, implemented and how it is being revised, and the interaction needs of the various actors in the process of EII. It also discusses the requirements for an integrated and comprehensive education and the level of teacher preparation for implementation of this model. It is suggested that questions about the importance of the teacher as implementer, analyzer, a catalyst for improvement and learning, ultimately, lead player in the EII and search to the final note that improvements can still be made to the "filter" through which every student passes is increasingly effective in its function.
\end{abstract}

KEYWORDS: Integral Education. Implementation. Teacher.

\section{Resumen}

\footnotetext{
* Graduada em ciências biológicas, mestrado em biologia, doutorado em agronomia. Professora da Universidade Federal de Goiás (UFG). Email: mercesmendonca@yahoo.com.br.

* Graduada em Ciências Sociais pela Universidade Federal de Goiás (UFG), especialista em História Cultural pela Universidade Federal de Goiás (UFG), mestre em Antropologia Social pela UFG. Email: iolenelobato@gmail.com.

* Graduada em Administração pela Universidade Católica de Goiás (UFG), mestre em Administração pela UNISINOS.
} 
El artículo discute el papel del educador en la educación integral e integrada en Brasil. Se pretende analizar cómo se construyó, implementó y cómo se está revisando el modelo integral, así como las necesidades de interacción de los diferentes actores en el proceso de EII. También analiza los requisitos para una educación integral e integrada y el nivel de preparación de los maestros para implementar este modelo. Se plantean preguntas sobre la importancia del docente como implementador, analizador, catalizador de mejoras y aprendizajes, en definitiva, protagonista del proceso EII y se busca al final enfatizar que aún se pueden hacer mejoras para que el "filtro" por el cual cada alumno pasa es cada vez más eficaz en su función.

PALABRAS CLAVE: Educación Integral. Implementación. Profesor.

\section{INTRODUÇÃO}

A palavra integral pode significar inteiro, completo, total. Uma educação integral seria, portanto, completa. Aquela que pense o ser humano por inteiro e em todas as dimensões. Para atendê-la, buscou-se ampliar de quatro para até no mínimo sete, as horas que as crianças e jovens passam na escola, garantindo o acesso e o direito a diversas atividades: arte, esporte, lazer, cultura, conteúdos pedagógicos, científicos, profissionalização, dentre outros (BRASIL, 2009; CARNEIRO, 2007). Essa ampliação implica em mais tempo na escola e estrutura mais adequada para esta permanência de crianças e jovens.

Assim a palavra integral relaciona-se com a ampliação dos turnos escolares e suas implicações. A palavra integrada pode garantir às crianças e adolescentes ${ }^{1}$ melhores oportunidades educativas através da ampliação direcionada dos turnos de estudo e da integração dos diversos saberes. Acredita-se que os alunos terão maiores oportunidades de desenvolver valores e atitudes que promovam a sociabilidade e a capacidade criativa, estimule o potencial cognitivo e propicie uma atitude positiva frente ao conhecimento e a vontade de aprender sempre mais (GAAC, 2012).

A concepção sobre o que é ou deva ser uma escola de educação integral e integrada ainda encontra-se em discussões. Sobre sua amplitude e atuação, contudo, existem pontos em comum, tais como a importância que se deve dar à articulação da educação intelectual com a atividade criadora, em suas mais variadas expressões, à vida social-comunitária da escola, à autonomia de alunos e professores; à formação global da criança (CAVALIERE, 2002). No Brasil, esses pontos nortearam as mudanças da escola tradicional, tornando essa escola em escola de educação integral e integrada de forma sistematizada, a partir do final do século XX e, ainda, continua em implementação em todo território nacional (BRASIL, 2009).

Segundo Moll (2008), falar em educação integrada significa considerar dois pressupostos básicos: o aspecto gratuito da escola e a articulação dos processos educativos contemporâneos a uma ampla rede de políticas sociais e culturais, de atores sociais e de equipamentos públicos. Nesse aspecto, é importante considerar que os processos educativos são teias de atores e merece uma repensar sobre o papel de um desses atores: o professor. Esse é o foco do trabalho aqui proposto.

\footnotetext{
${ }^{1}$ Ao público alvo da integração: Crianças de 07 a 12 anos, estudante da escola pública da alfabetização a $3^{\mathrm{a}}$ série do Ensino Fundamental, com dificuldades de aprendizagem (GAAC, 2012).
} 
Segundo Ribeiro (2007), aquele que um dia recebeu título de nobreza somente por sua formação para ensinar, encontra-se num novo momento da história, pois o professor

- $\quad$ está sujeito a massificação da informação;

- $\quad$ despreza as articulações e interações com o meio quando formado pelo modelo educacional clássico ${ }^{2}$,

- tem que responder pela responsabilidade pela educação dos alunos provenientes de família onde os pais são trabalhadores de 2 ou 3 turnos diários;

- encontra-se insatisfeito com o nível de reconhecimento de seu trabalho, especialmente no ensino público. Fato verificável em movimentos grevistas, paralisações e manifestações públicas em todo o Brasil; além da evasão dos cursos de licenciatura.

Desse modo, segundo Moll (2008) existe uma crise da instituição escolar refletida no adoecimento e licenciamento expressivo dos professores, de suas funções docentes, bem como com a ausência de diálogo entre esses e os pais. As ações não podem ser isoladas e nem trabalhadas de forma distinta. Assim, procura-se compreender como a situação atual se desencadeou e quais são os possíveis efeitos dessa crise no desempenho da função docente, especialmente na docência da educação integral e integrada (EII).

\title{
O professor na educação integral e integrada
}

Os idealizadores da educação nova de 1932, especialmente Anízio Teixeira, formataram o modelo educacional ideal para uma nação justa e democrática.

\begin{abstract}
Haverá escolas nucleares e parques escolares, sendo obrigada a criança a frequentar regularmente as duas instalações. O sistema escolar [...] funcionará em dois turnos, para cada criança [...] no primeiro a criança receberá, em prédio econômico e adequado, o ensino propriamente dito; no segundo receberá, em um parque-escola aparelhado e desenvolvido, a sua educação propriamente social, a educação física, a educação musical, a educação sanitária, a assistência alimentar e o uso da leitura em bibliotecas infantis e juvenis. (TEIXEIRA, 1997, p. 243).
\end{abstract}

Promover a interação entre a criança e seu meio, fará com que ela se torne sujeito no processo educacional, aproximando-a dos espaços sociais e, consequentemente, do espaço educacional no qual a educação integral seja real, contribuindo ainda mais para sua formação em quanto cidadão. Para tanto, a educação integral necessita de pessoas que saibam o que fazer e como fazer e que concebam a educação infantil como parte da formação do ser.

\footnotetext{
${ }^{2}$ Modelo clássico: instituído ainda na antiga Grécia (assimilado em parte pelo império Romano), no qual a teoria e a prática eram, além de distintas, dirigidas a públicos distintos. Enquanto essa era direcionada a classes sociais menos favorecidas, aquela era dirigida à elite, pensadora e formadora e opinião (BRANDÃO, 1993).
} 
Para tanto, ressalta-se importância do papel do professor na escola de tempo integral. Ele é uma figura importante dentro do processo educacional e o seu papel pode ser pensado a partir das seguintes perguntas: quem vai "fazer acontecer" um ensino integral e integrado na escola? Este profissional é protagonista das rápidas mudanças educacionais ocorridas na educação integral? Sua importância está relacionada aos demais atores educativos e merece destaque?

Segundo Moll (2008) a resposta para todas as questões é a mesma: sim.

Os professores são protagonistas dessa (nova) história da educação brasileira e o trabalho pode e deve ser pensado a partir da promoção do diálogo entre saberes diferenciados, reconhecendo que as experiências educacionais se desenvolvem dentro e fora das escolas. O professor deve ficar atento para cada aspiração que cada comunidade possui para si mesma e deve respeitar e incentivar essas escolhas.

Mas como formar esse professor?

Hoje existem ações dirigidas à formação e atualização de professores em diferentes níveis, mas em algumas visitas não programadas a escolas demonstram que ainda são poucas as mudanças nas práticas de ensino que podem ser consideradas significativas, bem como a qualidade da aprendizagem para muitos estudantes. Algumas razões podem explicar tal situação: o fato de que as ações de formação tendem a ter caráter pontual, acontecem em períodos muito curtos, não considerando as necessidades dos docentes e, na maioria das vezes, está desvinculada das práticas educacionais da escola.

Neste aspecto, merece ressalva o programa Mais Educação, que pode ser considerado um instrumento para a articulação desses atores em prol da educação pública e de qualidade. Para a implementação desse programa é necessário a escolha de um professor para desenhar a proposta do projeto. Esse profissional é o professor responsável por mediar as relações escola/comunidade. O seu objetivo é formular, em conjunto com as diversas forças atuantes nos territórios, um projeto de educação integral que nasça da relação entre desafios e vocações locais. Para construir esta ação coletiva é preciso um profissional com características muito específicas, tais como:

1 - ser um professor que já tenha relações com a comunidade - que seja parte dela, que conheça seus líderes, vocações locais, os equipamentos públicos, como clubes, igrejas, bibliotecas, museus, outras escolas, centros culturais, centros comerciais, fábricas, praças etc.;

2 - conhecer a história local, ou seja, saber que cada comunidade possui um modelo de si mesma e uma aspiração, um sonho a alcançar;

3 - incentivar o envolvimento da comunidade via projeto, de modo a favorecer a transformação da escola e comunidade através do enfrentamento das diferenças e da ampliação da esfera da negociação e diálogo;

4 - ser sensível às diferenças dos tempos individuais e coletivos e desenvolver o projeto gradativamente;

5 - deve criar um ambiente agradável de confiança e respeito mútuo entre professores da escola e membros da comunidade. 
Desse modo, o professor deve considerar as características da comunicação local, procurando valorizá-las. Afinal, o desafio maior do professor é promover o diálogo, falar várias línguas sociais, qualidade indispensável para um bom profissional. Ele deve ser um bom comunicador que consiga conversar e negociar em espaços da comunidade. Deve ter capacidade de convocar diferentes atores sociais e de fazê-los experimentar, na prática, a ideia de que a conquista da qualidade da educação pública passa pela mobilização.

Esse novo modelo escolar nasce, basicamente, sob duas vertentes:

a) como resposta à generalização e laicização da educação escolar alcançada, na Europa e nos Estados Unidos, em fins do século XIX e

b) como conseqüência dos avanços da biologia e da psicologia, que embasavam uma nova visão da criança, da aprendizagem, da educação em geral e da educação escolar (CAVALIERE, 2002).

Assim, o foco principal dessa mudança está centrado nas necessidades da sociedade "demanda por inteligência", fundamental ao crescimento e desenvolvimento social. Fato que também se torna relevante à medida que se procura entender a importância da figura docente no processo educacional.

Segundo a proposta da EII adotada no Brasil, outro ponto relevante ao entendimento desse novo modelo de escola e sua relação com o educador é que, o que ocorre dentro do espaço escolar, deve ser qualitativamente semelhante ao fenômeno global de vida/experiência/aprendizagem que caracteriza a própria condição humana. $\mathrm{O}$ que implica em afirmar que os professores da EII devem, em conjunto com os demais atores, transformar a escola em uma "micro-sociedade". Ou seja, propor uma prática escolar onde experiências reais ocorram; onde relações interpessoais se estabeleçam em diversos níveis e onde os aprendizados científicos e para as vidas pública e privada aconteçam de maneira integrada (CALAVIELE, 2002).

Dessa forma, a escola deve ser um ambiente de vivência e aprendizado e a vivência do aluno deve ser a base para seu aprendizado, rompendo com o modelo de transmissão de informações. Pode-se pensar que quando esta vivência não ocorre de maneira apropriada, pode gerar uma escola de tempo integral sem a devida integração, só com ampliação de turno.

É interessante ressaltar que em detrimento de toda estruturação e planejamento que devem ocorrer na implementação de um modelo de EII, o papel do professor está diretamente relacionado com sua capacidade em proporcionar vivências e/ou experiências sobre o conteúdo ministrado. Para tanto, pressupõe-se que suas vivências devam ser condizentes com o conteúdo e esse, ter relação com as experiências dos alunos, a partir da vivencia de cada um.

Para cada modelo educacional, um modelo docente é esperado. Tal fato pode ser refletido em estudo elaborado por Murta (2012) sobre as teorias que embasam o papel do professor e demais atores da educação, nos diversos modelos educacionais. Esse estudo também pode auxiliar o entendimento sobre o papel efetivo e esperado do professor na EII a partir de sua própria vivência e conteúdo: 


\section{Quadro 1 - Tendências pedagógicas X práticas educativas}

\begin{tabular}{|c|c|c|c|c|c|}
\hline $\begin{array}{l}\text { Tendências } \\
\text { Tradicional }\end{array}$ & $\begin{array}{l}\text { Papel do Professor } \\
\text { Implementar ações } \\
\text { Vigiar / Corrigir } \\
\text { Aconselhar }\end{array}$ & $\begin{array}{c}\text { Papel do } \\
\text { Aluno } \\
\\
\text { Memorizar } \\
\text { conhecimento } \\
\text { ouvir c/ } \\
\text { atenção. Fazer } \\
\text { exercícios }\end{array}$ & $\begin{array}{l}\text { Conteúdos } \\
\text { Escolares } \\
\text { Fatos e conceitos } \\
\text { científicos das } \\
\text { disciplinas } \\
\text { escolares }\end{array}$ & $\begin{array}{c}\text { Metodologia } \\
\text { Didática } \\
\text { Exposição oral } \\
\text { pelo professor }\end{array}$ & $\begin{array}{c}\text { Função de Avaliação } \\
\text { Selecionar } \\
\text { Classificar/Contabilizar }\end{array}$ \\
\hline $\begin{array}{c}\text { Renovada / } \\
\text { Nova }\end{array}$ & $\begin{array}{c}\text { Facilitar a } \\
\text { aprendizagem } \\
\text { Coordenar atividade } \\
\text { Apoiar }\end{array}$ & $\begin{array}{l}\text { Participar } \\
\text { ativamente } \\
\text { Pesquisar } \\
\text { Demonstrar } \\
\text { curiosidade }\end{array}$ & $\begin{array}{c}\text { Temas de } \\
\text { interesse do } \\
\text { aluno } \\
\text { Temas da vida }\end{array}$ & $\begin{array}{l}\text { Descoberta } \\
\text { pelo aluno } \\
\text { Passos do } \\
\text { método } \\
\text { científico }\end{array}$ & $\begin{array}{c}\text { Acompanhar o processo } \\
\text { de desenvolvimento do } \\
\text { aluno }\end{array}$ \\
\hline Tecnicista & $\begin{array}{l}\text { Implementar ações } \\
\text { Aplicar materiais } \\
\text { instrucionais/Controlar }\end{array}$ & $\begin{array}{c}\text { Dar respostas } \\
\text { programadas } \\
\text { Reagir a } \\
\text { estímulos } \\
\text { externos }\end{array}$ & $\begin{array}{l}\text { Fatos Conceitos } \\
\text { Princípios } \\
\text { científicos } \\
\text { fragmentados }\end{array}$ & $\begin{array}{l}\text { Aplicação de } \\
\text { materiais } \\
\text { instrucionais } \\
\text { pelo professor }\end{array}$ & $\begin{array}{c}\text { Medir } \\
\text { Controlar }\end{array}$ \\
\hline $\begin{array}{l}\text { Libertadora } \\
\text { Crítico- } \\
\text { social }\end{array}$ & $\begin{array}{l}\text { Mediar a construção do } \\
\text { conhecimento } \\
\text { Provocar, desafiar, } \\
\text { problematizar } \\
\text { Criar situações de } \\
\text { aprendizagem }\end{array}$ & $\begin{array}{l}\text { Pensar, refletir } \\
\text { Interpretar } \\
\text { experiências, } \\
\text { vivências } \\
\text { Buscar } \\
\text { informações }\end{array}$ & $\begin{array}{l}\text { Pensar, refletir, } \\
\text { interpretar } \\
\text { experiências, } \\
\text { vivências. } \\
\text { Buscar } \\
\text { informações } \\
\text { Processar } \\
\text { informações, } \\
\text { fatos, conceitos, } \\
\text { princípios, } \\
\text { normas, } \\
\text { procedimentos, } \\
\text { valores, atitudes } \\
\text { Conhecimentos } \\
\text { científicos e } \\
\text { experiências } \\
\text { socioculturais } \\
\text { vistos de forma } \\
\text { globalizada }\end{array}$ & \begin{tabular}{|c} 
\\
Diálogo \\
Construção \\
coletiva do \\
conhecimento \\
Interações \\
entre os \\
sujeitos no \\
processo de \\
conhecimento \\
\end{tabular} & $\begin{array}{c}\text { Diagnosticar e regular as } \\
\text { aprendizagens } \\
\text { Orientar as intervenções } \\
\text { pedagógicas } \\
\text { Acompanhar o } \\
\text { desenvolvimento do } \\
\text { aluno }\end{array}$ \\
\hline & & & & & \\
\hline
\end{tabular}

Percebe-se que os verbos: facilitar, coordenar, descobrir, mediar, provocar, desafiar, problematizar, criar e dialogar representam algumas das ações que esses profissionais devem conduzir em sala de aula e fora dela, considerando o modelo de escolas-parque, proposto por Anísio Teixeira, bem como a própria interação com o meio, prevista na EII. 
De acordo com o quadro acima é possível afirmar que em detrimento da "evolução" da pedagogia, da prática pedagógica e do papel do professor, as universidades, "provedoras" do profissional docente para o ensino fundamental, em função de razões históricas não mencionadas aqui, permaneceram desprestigiando o espaço escolar até a década de 1980, identificando-o como lugar menor do saber.

Assim, também, é entendida a importância do papel do professor como protagonista das práticas educativas e parece que existe uma separação entre a concepção oficial de formação e qualificação do profissional do ensino fundamental e o contexto vivenciado pelo professor.

Para a viabilização destas necessidades, os professores (bem como os demais profissionais do grupo escolar) devem ser orientados quanto aos princípios, objetivos e metodologias a serem desenvolvidas no âmbito da escola de horário integral. Essa preocupação em se trabalhar com o profissional docente pauta-se, principalmente, na fala de Darcy Ribeiro (1986, p. 83): "a ação pedagógica que se pretende imprimir ao ensino público no Rio de Janeiro pressupõe o engajamento ativo e consciente do professor de sala de aula, pois dele depende o sucesso da proposta do Programa Especial de Educação" (MONTEIRO, 2009).

É um novo modelo de docente capaz de lidar com crianças ali presentes - e não mais com o aluno ideal, oriundo das camadas ricas e médias da sociedade. Diferentes profissionais da educação, que permanecessem o dia inteiro na escola em jornadas de 40 horas semanais. O que implicaria em mais tempo para planejamento de suas atividades, bem como para a reflexão sobre sua prática e, ainda, enfrentar os desafios que se apresentem. Desafios como a necessidade de aprender a trabalhar com profissionais com outras formações e experiências. Também é necessário que os professores, além de conhecer a proposta da EII, se engajem politicamente na ação educativa ali realizada, que ampliem o seu olhar sobre o mundo e façam a leitura crítica da realidade sociocultural, abertos para o diálogo com a produção contemporânea difundida na mídia, na literatura, no cinema, na internet (MONTEIRO, 2009).

Para alcançar essa escola de tempo integral e integrada que queremos cabe a cada ator desse meio abrir-se para os saberes locais, de forma a transformar a educação numa prática comunitária. Para isto é necessário reunir todos os envolvidos nesta tarefa e ampliá-la a espaços diferentes e diversos da cidade e do território onde está localizada a escola. Nesse sentido, alguns estudos no campo educacional têm conduzido à conclusão de que políticas públicas, ao visarem à melhoria da qualidade do ensino, devem necessariamente propor a ampliação de olhares sobre o que é a instituição escolar e seu lugar na contemporaneidade. Tal concepção implica a constante reflexão e a adoção de medidas inovadoras para que a formação dos indivíduos contemple as suas dimensões curriculares e extracurriculares, os saberes e desafios escolares, bem como os saberes e desafios comunitários ou locais. A educação integral desafia-nos a construir e ampliar nossas trocas e diálogos entre escolas e comunidades. Para isto é necessário reconhecermos as distâncias que ainda marcam essas relações (MOLL, 2009).

\section{CONSIDERAÇÕES FINAIS}

Ensinar constitui a atividade principal na profissão do docente e por isso deve ser compreendida como uma arte que envolve aprendizagem contínua e envolvimento 
pessoal no processo de construção de novas experiências educacionais, as quais preparam o docente para resolver pendências no cotidiano escolar. Diante deste quadro é preciso repensar alguns fatos sobre o professor da educação integral e integrada: a maioria dos docentes formou-se e continua sendo formada com base em uma perspectiva tradicional uniformizadora da ação docente que se concentra na transmissão de conteúdos fragmentados entre si, os quais tendem a não apresentar relevância social para o estudante.

E a atual formação docente não cria bases para o desenvolvimento profissional contínuo dos docentes no que tange ao seu papel de educador e nem se articula com o aperfeiçoamento de práticas de ensino pedagogicamente mais efetivas.

Assim, é preciso propor ações que auxiliem os docentes na reflexão e revisão de suas concepções e práticas educacionais, atitudes e crenças visando a transformação de suas práticas de ensino em sala de aula. A proposta de Educação Integral e Integrada é uma possibilidade.

\section{REFERÊNCIAS}

BRANDÃO, Carlos Rodrigues. O que é educação. São Paulo: Brasiliense, Coleção Primeiros Passos, 28. ed., 1993.

BRASIL. Educação integral: texto referência para o debate nacional. Brasília: MEC, Secad, 2009.

CADERNOS Cenpec Educação Integral. Ano I, número 2, 2006.

CANDAU, Vera Maria. Reinventar a escola. Rio de Janeiro: Vozes, 2000.

CANCLINI, Nestor Garcia. Diferentes, desiguais e desconectados. Rio de Janeiro: Editora UFRJ, 2004.

CAVALIERE, Ana Maria. Educação Integral: uma nova identidade para a escola brasileira? Revista Educação e sociedade. Campinas, vol. 23, n. 81, p. 247-270, dez. 2002. Disponível em:< http://www.cedes.unicamp.br>. Acesso em 24 jan. 2012.

Quantidade e racionalidade do tempo de Escola: debates no Brasil e no mundo.

Revista Teias: Rio de Janeiro, ano 3, n. 6, p.1-14, jul/dez 2002.

CARNEIRO, Vera Maria Oliveira. Educação do campo integral na perspectiva do semi-árido. Disponível em: <http://www.moc.org.br/artigos/11-092007_10_51_20.pdf>. Acesso em: 25 jan. 2012.

GAAG. Disponível em: <http://www.gacc.org.br/site/index.asp?Conteudo_ID=5\&Sub_ID=33\&T=N\&P=1> Acesso em: 24 jan. 2012. 
GERMANI, Bernadete. A educação de tempo integral: passado e presente na rede municipal de ensino de Curitiba. 2006. 108 p. Dissertação (Mestrado em educação) PUCPR, Paraná, 2006.

LIMONTA, Sandra Valéria; MORAIS, Beverly Batista de. Ensino e aprendizagem de Ciências Naturais nos Anos Iniciais do Ensino Fundamental nas escolas de tempo integral em Goiânia. In: LIBÂNEO, José Carlos; SUANNO, Marilza Vanessa Rosa; LIMONTA, Sandra Valéria. (Org.). Didática e práticas de ensino: texto e contexto em diferentes áreas do conhecimento. Goiânia - GO: CEPED/PUC GO, 2011, v. 1, p. 53 64.

MOLL, Jaqueline. Conceitos e pressupostos: o que queremos dizer quando falamos de educação integral? Educação integral na perspectiva da reinvenção da escola: elementos para o debate brasileiro. Disponível em:

<tvbrasil.org.br/fotos/salto/series/173859Edu_int.pdf>. Acesso em: 06 jan. 2011.

Reinventar a escola dialogando com a comunidade e com a cidade: novos itinerários educativos. Revista Pátio. Porto Alegre: Artmed, ano VI, n.24; 2009.

MONTEIRO, Ana Maria. Ciep - Escola de Formação de Professores. In.: Aberto, Brasília, v. 22, n. 80, p. 35-49, abr. 2009.

MINAS GERAIS. Disponível: em $<$ http://crv.educacao.mg.gov.br/sistema_crv/index.asp?id_projeto=27\&ID_OBJETO=3 $5641 \&$ tipo $=\mathrm{ob} \& \mathrm{cp}=003366 \& \mathrm{cb}=\& \mathrm{n} 1=\& \mathrm{n} 2=$ Biblioteca $\% 20$ Virtual $\& \mathrm{n} 3=$ Dicion $\%$ E1 rio $\% 20 \mathrm{da} \% 20>$. Acesso em: 24 jan.2012.

MOTA, Silvia Maria C. Escola de tempo integral: da concepção à prática. V I SEMINÁRIO DA REDESTRADO - Regulação Educacional e Trabalho Docente 06 e 07 de novembro de 2006 - UERJ - Rio de Janeiro - RJ. Disponível em <www.fae.ufmg.br/estrado/cd.../eixo...1/escola_de_tempo_int.doc>. Acesso em: 22 jan. 2012.

RIBEIRO, Maria Luiza Santos. A história da educação brasileira: a organização escolar. 20. ed. Campinas, SP: Autores associados, 2007.

TITTON, Maria Beatriz Paupério. Profissionais da educação integral: que atores e que formação entram nesse jogo? Diálogos necessários para um projeto de Educação Integral. Disponível em:<tvbrasil.org.br/fotos/salto/series/173859Edu_int.pdf >. Acesso em: 06 dez. 2011.

Recebido em: 28/02/2019

Aprovado em: 26/04/2019 